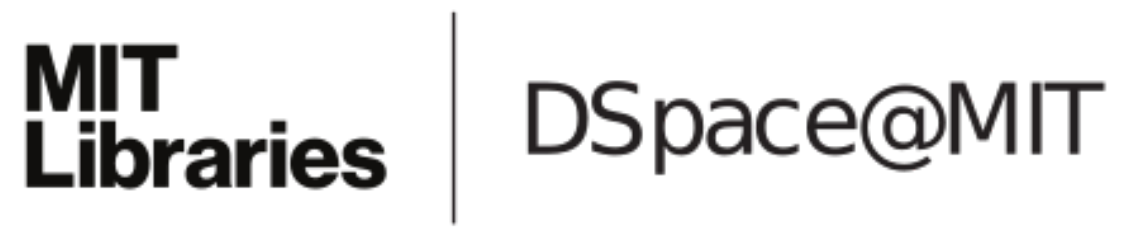

MIT Open Access Articles

Rich or thin?

The MIT Faculty has made this article openly available. Please share how this access benefits you. Your story matters.

Citation: Siegel, Susanna and Alex Byrne. "Rich or Thin?" In Current Controversies in Philosophy of Perception, [edited] by Bence Nanay, Routledge-Taylor \& Francis Group, 2017 (May 8, 2017): pp. 59-80..

As Published: http://dx.doi.org/10.4324/9781315733029

Publisher: Routledge-Taylor \& Francis Group

Persistent URL: http://hdl.handle.net/1721.1/116197

Version: Author's final manuscript: final author's manuscript post peer review, without publisher's formatting or copy editing

Terms of use: Creative Commons Attribution-Noncommercial-Share Alike 


\section{Rich or Thin?*}

\section{Susanna Siegel and Alex Byrne}

\section{PART 1: Siegel}

We see things. When we see things, they look a certain way. The conscious aspects of seeing include things' looking to us the way they do. These plain observations make it natural to ask how things may look to us in conscious perception, when we see them. Perception is often dense with social information. Headed for the top floor, you wait for the elevator. The door opens. Someone else is in it already. At the moment he sees you, fear and tension grip his body. Your presence makes him uncomfortable. His discomfort is palpable. He clutches his belongings. He won't meet your eyes. You realize that in his mind, it's a live possibility that you - a stranger to him in a small public space-might do something awful during the brief elevator ride.

What sets off these micro-interactions is visual perception. The man in the elevator first saw you as you stepped in to join him. But when he saw you, what did he see?

One way to make this question more exact is to ask which properties can be presented to you in your visual experience. Which properties characterize the ways things visually appear to you, when you see them? We can draw an initial division by putting colors, textures, spatial relations, shapes (including volumes), luminance, and motion on a list. The division helps define two opposing answers to our question.

According to the Thin View, the only properties presented in experience are limited to the ones on the list, which we can call 'thin properties'. There are no thin properties other than the ones listed. According to the Rich View, the properties presented in experience can include properties that are not on the list. We can call non-thin properties 'rich properties'.

The list that defines these two positions is somewhat arbitrary. But it is motivated by three related ideas.

\footnotetext{
* Thanks to Ned Block, David Hilbert, Zoe Jenkin, Eric Mandelbaum, Matt McGrath, Bence Nanay, Sarah Paul, and Bas Rokers.
} 
First, the properties on the list are computed by early vision in both humans and other animals. ${ }^{1}$ Since the visual system is typically sensitive to these properties, they plausibly end up characterizing at least some of the conscious aspects of vision.

Second, if one comes to perceive properties left off the list, plausibly one does so in part by perceiving the properties on the list. For instance, if watching a softball game leads one to think that the batter's swing sent the ball flying, one attributes causal efficacy to the bat (and to the batter) in part by seeing their position relative to the ball, their shape, and one saw those things in part by seeing the illumination and color contrast of those items. If color and illumination were undifferentiated from their surroundings, one would not be able to see them individually at all. If any properties are presented in experience, then presumably the thin properties are.

Finally, the great majority of properties that can figure in instantaneous impressions formed in the course of perception are left off the list. Think of causal properties, kinds, affordances, traits, appraisals. All of these properties figure in your instant impression of the elevator scene, and none of them are on the list. The list therefore lets us probe the relationship between visual experiences and instantaneous impressions.

There is another advantage to defining the debate by using a list of properties. When the Thin View is defined by a list, it is kept distinct from the position that the only properties presented in experience are those that are detected by the visual system. (At a finer level of grain, we can distinguish early vision from late vision, and at a coarser level, we can ask which properties are detected by perception in any combination of sensory modalities). We don't need to make a list of properties to state these positions. And the properties detected by the visual system could conceivably include rich properties - such as the property of being a face, or the property of expressing fear, or causal properties. It is therefore a different debate.

Thin vs. Rich: Can rich properties be presented in experience?

\footnotetext{
${ }^{1}$ See Pylyshyn 1999.
} 
Intra vs. Extra-visual: Can properties that are not detected by the visual system alone be presented in visual experience?

These two debates are in turn distinct from a neighboring question: in the human mind, where are the boundaries, if there are any, between perceptual and non-perceptual processing?

The current exchange concerns the first debate, between the Thin View and the Rich View. Like any debate, this one rests on starting assumptions. It takes as understood the category of visual experience, construes it as a phenomenological category, and goes on to ask which properties can be presented in that type of experience. The two positions in this debate are not the only options. Maybe no properties are presented in experience. Or maybe only some of the thin properties are. ${ }^{2}$ Or, finally, maybe nothing is denoted by the category of visual experience, so the debate between Thin and Rich Views gets no traction. But the starting assumptions of the debate are plausible: there are conscious aspects of seeing, and when we see things, they look a certain way. The ways they look are most naturally characterized by talking about the properties that things look to have. According to the Thin View, when the elevator opens and the man inside first sets his eyes on you, the changes in his visual experience are limited to changes in thin properties. And when you, in turn, see the fear and tension grip his body, you are not visually presented with the properties of being afraid or tense. The Thin View entails that in any visual experience, no matter what external scenes one is seeing, one is only ever presented with the highly circumscribed set of properties on the list.

Each party in the elevator takes in social complexities of the situation by visual perception. An initial motivation for the Rich View is that it easily respects the central role that visual experience plays in the overall experience of the people in the elevator. The Rich View allows that the man in the elevator, when he sees you waiting for the elevator in the hallway, is presented in his visual experience with other properties, including the property of being a person, a hallway, an entering or an exit. It allows that visual experience can attribute psychological properties to the people one sees, including:

\footnotetext{
${ }^{2}$ For instance, Thau (2002) denies that color is presented in experience.
} 
traits such as being kind, welcoming, or aggressive; age properties such as being a child, a young adult, or a grownup; kind properties such as being a person, or a bird, or being male; emotions such as sympathy, fear, boredom, pride, or suspicion; appraisals such as disdain or approval; agential (and causal) properties such as walking intentionally, tripping accidentally, or running with effort; interpersonal relations such as understanding what a person is hearing, or failing to comprehend it; and opportunities for action and interaction, such as the affordance of friendly chit-chat, tight-lipped isolation, or cooperative inquiry. When we set out to characterize a perceptual situation from the point of view of the subject of visual experience, rich properties are the ones that come to mind. With only thin properties at our disposal, most experiences would be unrecognizable.

For the moment, let's use the locutions 'looks F' and 'looks to be G' in a way that doesn't have to track exactly the properties presented in visual experience. We can leave open exactly what this use of 'looks' does track. Zero in on just one rich property: being scared. When 'looks' is used in this neutral way, both positions can agree that to you, the man in the elevator looks scared. The positions will differ in the role played by visual experience the man's looking scared to you. The Rich View has a straightforward analysis of this role: your visual experience can present the property of being scared. (The Rich View doesn't have to offer this analysis, but it can). The Thin View has to somehow bridge the gap between being the man's looking scared to you, and being presented with thin properties.

There are three strategies the Thin View can use to analyze X's looking scared to S. First, it can try to identify a set of thin properties that is co-extensive with being scared.

Presenting that set of properties (and attributing them to $\mathrm{X}$ ) is a good thin candidate for the properties presented in S's experience, when X looks scared to S. Second, it can try to identify a set of thin properties that X can visually appear to have, when X looks scared, and presenting any of those complexes (and attributing them to $\mathrm{X}$ ) suffices for $\mathrm{X}$ to look scared to S. Third, it can hold that there is no such set of properties, and "looking scared" never occurs entirely in visual experience. Here the Thin View must use other resources to analyze what it is for $\mathrm{X}$ to look scared to $\mathrm{S}$. The third option, however, runs up against 
the plausibility of the idea that for the case of looking scared, as for many other rich properties, looking scared seems to occur entirely in visual experience.

A second motivation for the Rich View is that for many rich properties F, the Thin View seems to lack resources to analyze cases in which X looks F to S. Consider the property that a loaf of bread has of being sliced by a knife. The knife cuts the bread. Cutting is a causal property. The knife also moves back and forth, as a piece of bread gradually separates from the rest of the loaf. These are (thin) spatio-temporal properties. If only thin properties were presented in the visual experience of seeing the bread get cut the knife, then for all your visual experience tells you, the bread's separation may be making the knife move. Pressure is also a causal property. If only thin properties were presented in the visual experience of seeing a knife slicing bread, your visual experience should leave it open whether the knife is exerting pressure on the bread. It is clear that the knife looks to be cutting the bread, and so the experience as a whole is not neutral on the whether causation is occurring. Perhaps, someplace in the mind, there's a representation of the occurrence that is neutral on whether the knife is cutting the bread (or even just exerting pressure on the bread). The Thin View is committed to more than this. It's committed to finding a conscious experience in the mix that is neutral in just this way.

To avoid positing the rich properties of causation and exerting pressure as presented in visual experience, what if the Thin View divides visual perceptual experience from amodal, non-perceptual experience? This move would make room for the idea that we experience causation, without holding that we experience it visually-even when no other sense modality besides vision is involved. But there is no obvious principled division here. We know that there are perceptual experiences, such as conscious vision. Are there also amodal experiences, distinct from judgment, with all the phenomenological hallmarks of perceptual experience, yet which aren't perceptual? This suggestion sounds like a distinction without a difference. 


\section{PART 1: Byrne}

Suppose you are in Susanna's office and see a Granny Smith on her desk. You form some beliefs: that it is green and round, that it is an apple, that it is edible, and that Susanna likes apples. Suddenly a small piece of the apple, about the size of a pencil eraser, is extruded and falls on the floor, pushed by a caterpillar crawling out of the newly-made hole. You form the belief that the caterpillar caused the piece of apple to fall, and that the caterpillar is alive. You believe, then, these propositions:

(A) That it [the apple] is green and round.

(B) That it is an apple.

(C) That it is edible.

(D) That Susanna likes apples.

(E) That this [the caterpillar] caused that [the piece of apple] to fall.

(F) That this [the caterpillar] is alive.

Further, your beliefs are perceptual, in an intuitive sense. You believe propositions (A)(F) more-or-less immediately because of what you see-if your eyes had been closed you would not have believed any of them.

One way of putting the issue before us concerns the content of perceptual experience; another-closely related-way concerns the properties presented in perceptual experience. But what does this jargon mean? The "content" of a perceptual experience is often explained in these terms: it is a proposition (or set of propositions) specifying the conditions under which the experience is veridical. ${ }^{3}$ A property "presented in" perceptual experience is then a property attributed by the content of that experience, in the sense in which (C) attributes edibility, for example.

\footnotetext{
${ }^{3}$ It is controversial that perceptual experiences have content (see, e.g., Brogaard 2014). Moreover, some of those who agree perceptual experiences have content deny that it is propositional (see, e.g., Burge 2010: 36). However, the fundamental issue between Siegel and me arises for most philosophers of perception, even if they would deprecate the way we put it. (It is also less than clear what "perceptual experiences" are supposed to be, but that can of worms will be left closed.)
} 
Although in her opening contribution Siegel prefers to speak of properties "presented in experience", she is also happy talking of the "content of experience" (Siegel 2010), so let us stick with that for the next few paragraphs. Siegel and I agree that (A) is part of the content of your experience - if the apple is not green, or not round, then your experience is not veridical. We also agree that (D) isn't part of the content of your experience-if it turned out that Susanna did not, after all, like apples, the only error or mistake would lie in your perceptual belief.

However, everything else is in dispute. According to Siegel, the content of your experience includes (or, at least, could include) the other items on the list: (B), (C), (E) and (F). In general, she thinks that among the contents of experiences are propositions about kinds like apple, "affordances" like edibility, causation, and animacy. I do not. The crucial notion of the content of experience (and the derivative notion of the presentation of a property) was explained in terms of an experience's being "veridical". (Alternatively, we could have spoken of an experience's being "accurate" or "correct". ${ }^{4}$ ) But one might well complain that this is a case of obscurum per obscurius:

We do not naturally talk about visual experiences as being veridical or nonveridical, or accurate or inaccurate, or correct or incorrect. I very much doubt that the woman in the street would understand what I mean, were I to ask whether her current visual experience is veridical or non-veridical, or accurate or inaccurate, or correct or incorrect, at least not without some guess work. (Breckenridge 2007: 117)

Must do better, then. Let us see how Siegel explains the question up for debate. Siegel informally introduces the question using an example of a sinister elevator encounter:

The man in the elevator first saw you as you stepped in to join him. But when he saw you, what did he see? (xxx-xxx)

\footnotetext{
${ }^{4}$ Cf. Siegel 2010: 30-3.
} 
She then tries to make this question "more exact", but it's worth pausing to note why the extra effort is needed. Confronting the discomfited stranger in the elevator, you (a philosopher, we may presume) are visibly nervous. This is because you are taking the elevator to the ground floor of the depressing APA hotel to go to the book exhibit, where you plan to kill your publisher. The stranger takes note of your twitching, and sees that you are nervous. He has no idea that you are going to the book exhibit, so he does not see that you are going to the book exhibit. Nonetheless, because that is where you are going, and he sees you, he sees you going to the book exhibit. (Later, when he testifies in court at your trial, he will say 'Yes, your honor, I did see her going to the book exhibit, although I didn't realize it at the time'.5) So the question 'What the man in the elevator see?' has multiple answers: he saw that you were nervous, he saw you going to the book exhibit, he saw a philosopher with murder in her heart, etc. Further, none of these answers is (or need be) controversial. Whatever the question may be, to which Siegel and I give opposing answers, 'What did he see?' is not it.

As mentioned, Siegel's preferred way of putting the question du jour is (quite generally, leaving the man in the elevator behind): "which properties can be presented to you in your visual experience?" Because the notion of "presentation" requires explanation, this is immediately glossed as "Which properties characterize the ways things visually appear to you, when you see them?" (xxx-xxx). Equivalently, as suggested by her first paragraph: How do objects look?

To the man in the elevator, you look scary. Thus, one way objects (humans, for instance) can look is scary. 'Way' talk, as in 'the way she looks', is property talk - the ways are specified by adjectives: scary, nervous, middle-aged, wealthy, Scandinavian. So the question 'How did you look to the man in the elevator?' (i.e. 'What way did you look..?') has multiple answers: you looked scary, nervous, and (suppose) middle-aged and Scandinavian. Further, none of these answers is (or need be) controversial. Whatever the question may be, to which Siegel and I give opposing answers, 'How did you look to him'? is not it either.

\footnotetext{
${ }^{5}$ Cf. Barwise 1981.
} 
It is sometimes suggested that different "senses" of 'looks' can come to the rescue here, but standard tests for ambiguity indicate that this is misguided. To the man in the elevator you simply look scary and (say) pale and small; there's no sense in which you look pale and small but not scary. ${ }^{6}$

So if ordinary perceptual verbs are all we have to go on, the issue between us remains obscure. Do we have to lapse back into reliance on the jargon of "veridicality"? Well, sort of, but the situation is not quite as bad as Breckenridge, quoted above, makes out:

In Philosophy we often talk of sense experiences being either veridical or nonveridical. These are technical terms, but it is clear from the ease with which beginning students can learn to apply them that they answer to a genuine distinction. (Pendlebury 1990: 224)

Pendlebury's point can be strengthened by noting talk of "visual illusions" is reasonably familiar to the woman in the street. Striking examples of such are internet fodder and demonstrate how the term can readily be applied to new cases. And once the notion of an illusion is found acceptable, the complementary notion of a veridical experience has to be in good order too. ${ }^{7}$

Why is this folk-category important? Because it is closely linked to a widespread view in the scientific study of perception, that perceptual modalities like vision are modular in the sense of Fodor 1983. The (early) visual system's operation is mandatory (you see ${ }^{\longleftrightarrow}$ as two unequal lines whether you like it or not), fast, and informationally encapsulated (in particular, believing that the two lines are unequal does not affect the appearance of unequal lines). ${ }^{8}$ That modular architecture and the phenomenon of illusions fit together nicely: illusions are precisely cases where the output of the visual system fails to match reality. The present dispute is, I suggest, best understood in these terms.

\footnotetext{
6 See Thau 2002: 230 and Byrne forthcoming. Although 'looks [adjective]' is unhelpful, 'looks the same/different' is indispensable, as the rest of this debate illustrates.

${ }^{7}$ Hallucinations are a vexed category that can be ignored for present purposes.

${ }^{8}$ For some of the usual qualifications to encapsulation (to accommodate, e.g., cross-modal effects), see Burge 2010: 101-2.
} 
Assuming that there is a visual module (perhaps one less encapsulated that Fodor himself allows), we can locate the dispute at the level of its outputs. Do they concern kinds, affordances, causation, or animacy? And since the outputs are pieces of information (or misinformation), we may take them to be propositions. To return to the opening example, can the outputs of the visual module include propositions like $(\mathrm{B}),(\mathrm{C}),(\mathrm{E})$ or $(\mathrm{F})$ ?

As desired, there is plenty of fruitful controversy. Fodor, for example, aligns himself partly with Siegel, claiming that the outputs of the visual module include "basic perceptual categories" like dog and apple (94-7). But he disagrees with her in excluding subordinate categories like French poodle and Granny Smith.

Siegel and I may agree on this much: if the phenomena can be explained without imputing a certain kind of rich content to the output of the visual module, then there is no reason to impute it. The debate turns, then, on how much work thin outputs can do. 


\section{PART 2: Siegel}

If you asked someone on the street what kind of life promotes human flourishing, she would probably not use the Greek word 'eudaimonia' in her answer. Few English speakers possess this concept. It would be absurd to conclude from this observation that when Aristotle discussed this topic, he was on the wrong track. Philosophical horizons aren't set by English. They're set by the problems that life and abstracta (such as numbers) can pose.

If you asked the man in the elevator to describe his perceptual experience, he almost certainly wouldn't use the terms 'contents', 'properties presented in experience', 'veridical', 'accuracy condition', or even 'visual experience' in his answer. He might even wonder what you're asking. Most people are unfamiliar with the philosophical discussions of perception that use these terms. They're technical terms.

Byrne warns us to define these bits of philosophical jargon. Then he goes farther and suggests that it isn't obvious how to define them - and so the issue between the Rich and the Thin View should be reframed as a question about what the deliverances are of modular vision.

Not all uses of philosophical jargon are gratuitous. The problems of perception and intentionality are cases in point. Ponce de Leon is looking for the Fountain of Youth. How could his thoughts be coherent, given that there is no Fountain of Youth? Anscombe (1965) pointed out that an analogous question arises in perception. When the elevator man takes you to be threatening upon believing his eyes, he hallucinates or illudes a threatening demeanor. If we want to characterize his visual consciousness, we need to advert to something other than you and the properties you actually have. We cannot read off his perspective from the objects and properties in the world. A partial exception might be the relational property you have of producing his experience. But his experience is part of his perspective, and the relational properties take that perspective as understood, rather than providing a way to characterize it. 
Anscombe saw that theoretical resources beyond ordinary uses of English (and probably any other language) were needed to describe the subject's perspective in these cases. She thought the notion of an intentional object would help, because those objects had no reality beyond the subject's perspective. And it does help, up to a point. It gives us a vocabulary to indicate when we're describing the contours of consciousness. But because of its orientation to objects - one sees an F, one looks for the Fountain of Youthobscurities remain. If you're hallucinating a pink elephant and I am too, do our visual experiences have the same intentional objects? What if your elephant is sitting but mine is standing? If you think the Fountain of Youth is in Florida but I think it's in Alabama, are we looking for the same thing? Intentional objects are supposed to characterize how things are from the subject's perspective in thought or perception, but objectual locutions barely scratch the surface.

It helps to focus on properties rather than objects. It allows more specificity. And it allows us to label properties that don't have labels in ordinary English. Think of the elevator man's briefcase. There's a configuration of its protruding surfaces that you can see from where you happen to be standing. Beyond those facing surfaces, it continues out of view. English doesn't have a name of the shape formed by those facing surfaces, but that fact does not stop that shape from being presented to you when you look at the man's briefcase-even if you are an English speaker.

Another thing we need, if we want to characterize the perspective of perceivers, is a way to zero in on the mental state we're asking about. 'How things look to you when you see them' is just a placeholder, because the English word 'look' can denote too many things. 'Properties presented in experience' is better. It gives us a label for the mental state. And it gives us a tool for describing its character. The label might not be useful to Breckenridge's friend right off the bat, when he asks her if her experience is accurate. But that's because Breckenridge's friend, hit with this question out of the blue, presumably isn't already trying to zero in on the same thing as us. Once she understood that the mental phenomenon concerns a subject's perspective that can come apart from the way the world is, it would be natural to ask whether things are the way they're presented as being in her experience. 
Byrne suggests that the notion of visual illusion is tied to the thesis that early vision operates in a way that is mandatory given specific stimuli, and insulated from other psychological states, such as what the subject wants or believes. But visual illusion is a much broader category. Vision goes beyond early vision. And visual experience goes beyond visual illusions. If we worked with a definition of visual experience as an output (meeting specific conditions) of modular processing, it would be impossible to formulate a debate about whether every visual experience results from modular processes or not. It would also be impossible to ask whether rich properties can be presented in experience as a result of non-modular processes. It is better to work with notions of visual illusion and visual experience that leave these crucial questions open.

By refining the questions 'What does the elevator man see?' and 'How do you look to him'?, we can ask what perceptual experience contributes to our overall conscious state. There is no doubt that such contributions exist. When the Necker cube shifts, this isn't a change in how things smell to us. It's a change in how things look to us. There plainly is such a thing as the contours of visual consciousness. There is no need to appeal to modular processes to pin down the visual phenomena about which the Rich and the Thin Views disagree. Whether rich properties can be presented in experience is orthogonal to whether the processes that produced the experiences are modular or not.

Consider perceptual learning - long-term changes in perception that result from gaining or practicing a skill. Learning to speak and understand Russian will change how the spoken language sounds to you. Learning to recognize pine trees can change how a forest containing pine trees mixed among others look to you. For cases in which a single stimulus produces different perceptual experiences before and after perceptual learning, we have a phenomenal contrast between two experiences.

The phenomenal contrast gives us something to be explained. We can study the contrast by asking a series of questions. Is it a difference in which properties are presented in experience? If so, which properties differ? How these questions are answered depends on the phenomenal contrast one starts out with, and it depends which of the possible answers survive challenges of plausibility. 
Not every phenomenal contrast is best explained by the Rich View. Many will be explained by changes in thin properties. But to argue successfully for the Rich View, all it takes is one phenomenal contrast that the Rich View best explains. In The Contents of Visual Experience, I formulate a series of phenomenal contrasts and argue that each of them is best explained by a different instance of the Rich View: kind properties, causation, personal efficacy, and a type of mind-independence each play a role in explaining a different type of phenomenal contrast.

The contrast method doesn't care which processes produce the phenomenal contrasts. Controversies abound among psychologists over the extent to which what we want, suspect, or know (other than by perceptual learning) can alter the properties presented in perceptual experience. But these controversies usually concern the boundaries of perception, rather than the boundaries of perceptual experience. We can use the method of phenomenal contrast to test the hypothesis that rich properties are presented in experience, no matter how they come to be so represented. Nothing in the method stacks the deck in favor of the Rich View. 


\section{PART 2: Byrne}

In Siegel's preferred terms, the dispute between us concerns which properties are "presented in experience"; specifically, are the presented properties rich or thin? On the negative side, I complained that explanations of the terminology of 'presented property' in terms of 'sees' or 'looks' are inadequate, and that more was needed to clarify the dispute..$^{9}$ (This was not an application of the dubious principle that "philosophical horizons are set by English" (xxx). Neither was it an application of the equally dubious injunction to define one's terms.)

On the positive side, I suggested that a better route to clarification is via the notion of a visual illusion, a stock category on the internet (and in vision science) that is readily illustrated by examples, and generalized to new cases. Once the notion of a visual illusion is in hand, so is the complementary notion of a veridical perception, and the content of visual experience is not far behind. And granted that experience has content, we can use that to explain the notion of a property being "presented in" experience.

I also suggested that the dispute makes contact with vision science via perceptual modules, conceived along Fodorian lines. Modules (if there are such) plausibly align with illusions: an organism suffers a perceptual illusion just in case the output of a module, a piece of purported information about the organism's environment, is misinformation. Put in other terms, an organism suffers a perceptual illusion just in case the propositional content of its experience is false. If the modularity thesis is true, then this helps us to pin down the empirical considerations relevant to assessing the Rich View.

In reply, Siegel makes two points. First, she claims that "visual illusion is a much broader category" (xxx), implying that some visual illusions are not cases where the output of the visual module is false. I disagree. Of course one cannot discover the alignment between visual illusions and false visual module output from the armchair, but successes in explaining illusions in broadly modularist terms suggest that they do not come apart.

\footnotetext{
${ }^{9}$ Siegel doesn't entirely disagree with this, but she thinks the problem is that "the English word 'look' can denote too many things" ( $\mathrm{xxx}$ ). However, as I see it, the problem is that 'look' (at least as used in a perceptual way) only denotes one thing.
} 
Siegel's second point is that if "we worked with a definition of visual [illusion]" in terms of visual modules it would be "impossible to formulate a debate about whether every visual [illusion] results from modular processes or not" $(\mathrm{xxx})^{10}$, presumably because the answer would simply drop out from our stipulative definition of 'visual illusion'. But the proposal was not to define that phrase; rather, it was to link something in the manifest image with something in the scientific image, as rusting is linked with oxidation or the tides with gravity. Once we realize that there is an intimate connection between the tides and gravity, we can bring our theory of gravity to bear on answering questions about the tides; similarly, granted an intimate connection between the visual module and illusions, we can bring our theory of the visual module to bear on the issue of presented properties (themselves explained in terms of illusion).

Of course, although one can hardly deny that we have a visual system in some useful sense, one might well deny that there is anything like a Fodorian visual module. A large amount of research (most of it recent) seems to show that vision is highly cognitively penetrable - belief and other attitudes can influence how things look. ${ }^{11}$ (This is the return of the old "New Look" movement in psychology, the "New New Look", as Machery (2015) calls it.) Knowledge that lips are red makes a lip-shaped cutout look redder (Delk and Fillenbaum 1965; see also Macpherson 2012). Faces with stereotypically black features look darker than faces with stereotypically white features, equated for mean luminance (Levin and Banaji 2006). Holding a long rod horizontally, thus altering one's beliefs about how easy it is to pass through apertures, makes doorways look narrower (Stefanucci and Geuss 2009). And so on. However, this appears to be more confirmation that most published research findings are false (Ioannidis 2005). ${ }^{12}$ Gross et al. (2014) failed to replicate the Delk and Fillenbaum experiment. ${ }^{13}$ The perceptual difference

\footnotetext{
10 The actual quotation has 'visual experience' rather than 'visual illusion' but it is clear from the context that Siegel would accept the substitution.

${ }^{11}$ For a more careful statement of cognitive (im)penetrability, see Macpherson 2012: 28-9.

12 Although principally not for the reasons given by Ioannidis.

13 The replication was conceptual, not direct. There is other (more recent and much better) work on memory color than the flawed Delk and Fillenbaum study, e.g. Olkkonen et al. 2008, Witzel et al. 2011.
} 
between black and white faces, although perfectly genuine, turns out to be due to lowlevel features, not racial categories (Firestone and Scholl 2015). There is no change in how apertures look, and the contrary indication is likely a task compliance effect (Firestone and Scholl 2014). The Fodorian hypothesis is holding up pretty well. ${ }^{14}$ It is now time to consider particular examples. Imagine learning to visually recognize teacups. Before, faced with a teacup, you would exclaim 'What is that?' Now you see teacups as teacups, and immediately classify them as such. Let us grant that teacups now palpably look different. (This is not obvious, but plausibly it sometimes occurs in acquired perceptual expertise. ${ }^{15}$ ) There is what Siegel calls a "phenomenal contrast" between one's perception of teacups before learning to recognize them, and one's perception of teacups after learning to recognize them. One explanation of the phenomenal contrast is that, as a result of the learning period, the property teacuphood is presented in your experience-in other words, teacuphood figures in the content of your experience. As Siegel says $(\mathrm{xxx})$, this is the explanation that she endorses for cases for this sort (Siegel 2010: ch. 4). ${ }^{16}$

Olkkonen et. al found a memory color effect for realistic photographs of fruit, but not for outline fruit shapes. Using a similar methodology, Witzel et al. found a memory color effect for artificial objects with characteristic colors (e.g. smurfs, mailboxes, Nivea cream tins). (Interestingly, they found no effect for fire extinguishers (43).) Assuming that the effect is perceptual (for an alternative explanation see Zeimbekis 2013), what seems to be important is that the stimulus is visually similar to instances of the kind that have been previously seen, which suggests that "high-level" knowledge that bananas are yellow and smurfs are blue is not what is driving the effect. (See further Gross et al. 2014 and also Olkkonen et al. 2012.)

${ }^{14}$ A highly controversial claim, admittedly. For a brief skeptical review of the literature on cognitive penetration, see Machery 2015 (in the useful collection Zeimbekis and Raftopoulos 2015). For a lengthy systematic critique, see Firestone and Scholl forthcoming.

15 See, e.g., Schyns et al. 1998: 2-4. There is no conflict with modularity here, since a diet of certain inputs may cause modules to change over time.

16 This is a standard way of arguing for the Rich View; for references, see Bayne 2009: 390. 
A rival explanation is that a thin or "lower-level" property is presented, a complex shape/size/... property or a "teacup gestalt" (110-2). ${ }^{17}$ This complex property, which we can call teacuphood ${ }^{G}$, is not teacuphood. Teacups are only found embedded in the social practice of tea-drinking; a teacup ${ }^{G}$ may be found in the natural environment. A rock that by chance has the shape and size of a stereotypical teacup (and so is a teacup ${ }^{\mathrm{G}}$ ) is not a teacup; conversely, there may be unorthodox or damaged teacups that do not have that distinctive teacup shape. But teacuphood ${ }^{\mathrm{G}}$ is highly correlated with teacuphood; more precisely, teacups that are visibly recognizable as such invariably have teacuphood ${ }^{\mathrm{G}}$, and teacuphood $^{\mathrm{G}}$ is rarely instantiated in non-teacups. In Block's terminology, the two are recognitionally coextensive (Block 2014: 562-3).

Agreeing with Burge, Block thinks it improbable that teacuphood is perceptually presented (560). Why does Siegel think that the rich explanation is to be preferred? Her discussion in The Contents of Visual Experience does not purport to be conclusive. In the absence of a "knock-down argument" (Siegel 2010: 111), she offers two considerations. First, "shape-gestalts that are abstract enough to remain invariant across [teacups] will be invariant across other objects as well" (111) - perhaps coffee mugs and coffee cups (cf. 112). But this seems quite doubtful, because thin properties that differentiate between teacups and coffee mugs or cups are not hard to find. (For instance, teacups have small bases, unlike mugs, and are lower and wider than coffee cups.) Second, she suggests that "the strategy of invoking the representation-invariant color-shape complexes to underpin phenomenological changes does not seem generally available", and gives the following example in support. One might learn to recognize a doubtful facial expression, coming to believe that a certain facial contortion "is an expression of doubt only after repeated sightings of it and interaction with the person. This change in interpretation seems to be one that could be accompanied by a phenomenological change as well" (112). Maybe the person's face would look different, despite no corresponding change in presented thin

\footnotetext{
17 Siegel's actual example involves pine trees rather than teacups; that example is complicated by the fact that (ordinary) pine trees are visually more diverse than (ordinary) teacups. Even in the case of teacups, there is diversity - between English and Japanese varieties, for instance. To avoid an unnecessary complication, restrict attention to English teacups. (A more realistic example would involve a sub-category, say Royal Albert teacups, since perceptual expertise is more pronounced at these levels.)
} 
properties. But what we need at this point is an actual demonstration, which Siegel does not supply.

In favor of the alternative thin explanation, consider greebles, those vaguely elvish invented stimuli used to study object recognition. ${ }^{18}$ One can learn to recognize greebles as such; after the learning period, greebles look different, or so we may suppose. (One can learn to recognize individual greebles, as one may recognize individual faces, but to keep the parallel with teacups let us concentrate on recognizing instances of the kind.) What explains the "phenomenal contrast"? Could it be that greeblehood is not presented in the experience of the novice and is presented in the experience of the expert? That is surely a plausible explanation, but notice that greeblehood is a complex low-level property. To be a greeble is simply to have a certain shaped parts spatially arranged in a certain way: greeblehood $=$ greeblehood $^{\mathrm{G}}$. By design, there is no competing candidate explanation in terms of a rich property. There is nothing to threaten the Thin View here. Now imagine that the greebles we typically encounter are in fact fungi, groobles. Grooblehood $^{\mathrm{G}}=$ greeblehood But, just as teacuphood $\neq$ teacuphood $^{\mathrm{G}}$, so grooblehood $\neq$ grooblehood $^{\mathrm{G}}$ (i.e. greeblehood). Some groobles are not greebles, and some greebles are not groobles. Suppose, starting as a perceptual novice (in particular, not having a recognitional ability for either greebles or groobles) you learn to recognize groobles as such; after the learning period, groobles look different. What explains the phenomenal contrast? Granted the explanation given in the previous case, the most parsimonious hypothesis is that after the learning period, greeblehood (i.e. grooblehood $^{\mathrm{G}}$ ) is presented in your experience.

Siegel might counter by adapting her example of recognizing the doubtful facial expression, mentioned three paragraphs back. As immediately above, (typical) greebles are groobles. However, you are ignorant of this fact-as far as you know, there is no high-level unity to greebles, any more than there is to cubes. You learn to recognize greebles, and so greeblehood comes to be presented in your experience. Then, you discover that (typical) greebles are fungi, and gain the ability to visually recognize

${ }^{18}$ For illustrations, see https://en.wikipedia.org/wiki/Greeble_(psychology). 
groobles: you effortlessly come to believe that this is a grooble, on seeing one oriented properly in good viewing conditions. If "this change in interpretation" is "accompanied by a phenomenological change as well", then obviously the presentation of greeblehood can't explain it, since that has remained constant throughout. So the explanation must be that grooblehood has come to be presented in your experience, vindicating the Rich View.

It is here that the link with modularity is relevant. Notice that the rich explanation requires cognitive penetration. It is not the fact that you have perceptually encountered groobles that explains why grooblehood is presented, it is the fact that you know that these visually distinctive items are groobles. And since there is little reason to suppose that vision is penetrable (more cautiously, penetrable in this sort of way), the rich explanation should be rejected, along with the explanandum it was supposed to explain. The "change in interpretation" will not, after all, be accompanied by a change in how groobles look.

Even if the Rich View is not true for kinds, there are other candidates. Affordances are not especially promising, because they are typically too local and transient to be attributed by the outputs of encapsulated modules. ${ }^{19}$ The visual signatures of edibility, for example, vary from place to place and season to season. Causation and animacy are much better, and will be discussed in Part 3.

${ }^{19}$ However, for arguments that affordances are perceptually presented, see Nanay 2011 and Siegel 2014. 


\section{PART 3: Siegel}

Byrne thinks there's a "stock category" of visual illusion that can help define the Rich/Thin debate. In the illusion where a straight stick looks bent, the illusion concerns a thin property, bentness. Where there is visual illusion, there is visual experience. And where there is visual experience, there are (Byrne assumes) conditions under which that experience would be veridical. If the stick immersed in water really were bent, then the experience of it as bent would be veridical.

If the veridicality conditions of illusions ever include the instantiation of a rich property, then the Rich View is true. But what if the veridicality conditions of illusions only ever include thin properties? Should we then conclude that the Thin View is true?

No. Examining the contents of visual illusions found on the internet or in vision science textbooks (Byrne's sources for stock illusions) would be a poor method for deciding between Rich and Thin, because the visual experiences reach far beyond visual illusions and their veridical counterparts. We shouldn't expect to resolve the debate by checking all the stock examples of visual illusions. Once we know which mental states are the visual experiences, then we'll know which states of misinformation are visual illusions. But identifying the standard visual illusions isn't a way to carve out the class of visual experiences.

Even by Byrne's lights, the stock category of visual illusion isn't needed for the issue to make contact with vision science - contrary to his suggestion that the notion of illusion provides a better route to clarification than mine. Vision science, Byrne suggests, lays it down that there are "perceptual modules, conceived along Fodorian lines", and the informational outputs of those modules delimit the contents of visual experience. Byrne thinks that "modularity helps us pin down the empirical considerations relevant to assessing the Rich View" (xxx).

But the standard Rich/Thin debate cannot be assimilated to the debate about whether any outputs of perceptual modules are rich. Perceptual experience is a phenomenological category. Perceptual modules, in contrast, are defined functionally: they are, roughly, 
mandatory processes that always respond in the same way to a proprietary set of inputs. Nothing in the functional characterization of a module can speak to whether its outputs exhaust the conscious representations that constitute perceptual experience. (That characterization does not even speak to whether the outputs are conscious. If rich properties were unconsciously perceived via a module, that would not show that the Rich View is true.) Even if all the outputs of perceptual modules were thin, that conclusion would not entail the Thin View. And in any case, Byrne's confidence in modularism relies on a scattered list of rebuttals of putative counter-examples, ignoring many productive strands in vision research that do not rely on the presumption of modularity, and are oriented around the prima-facie anti-modularist idea that visual experience depends heavily on stored memory and past experience - and so is unlikely to be as insensitive to the rest of the mind as modularism predicts. ${ }^{20}$ The coherence of the Rich/Thin debate does not depend on whether modularism or the anti-modularism ultimately wins the day.

A different strategy would try to assimilate the debate to one about the outputs of exclusively perceptual processes - whether those processes are modular or not. This assimilation strategy falters in the same place as Byrne's modularist strategy: it does not bypass the need for assumptions about which states are perceptual experiences. We need to make such assumptions to bring the science of perception to bear on the Rich/Thin debate. Consider the interaction between shape and color found in one version of the memory-color phenomenon: a banana-shaped image appears more yellow than something of the same color that isn't banana-shaped.$^{21}$ Let's suppose that this effect is evidence that shape information can influence color information. Color processing does not then look to have its own, entirely encapsulated module. Which color you end up experiencing will depend on which shape information you take in. Presumably this observation shouldn't lead us to conclude that colors are not presented in experience. The fact that we have color experiences is a fixed point. If it turned out that some color processing wasn't

\footnotetext{
${ }^{20}$ See Greene and Oliva 2009, Triesch et al. 2003, and the papers by Feldman-Barrett and by Bar in Bar 2011.

${ }^{21}$ See Olkkonen et al. 2008.
} 
modular, or that it resulted from processes that didn't fit our antecedent assumption about which processes are perceptual, we shouldn't conclude that colors are not presented to us in visual experience. It's a phenomenological datum that they are.

My phenomenal contrast method provides a framework in which we can locate considerations from vision science. The method allows us to distinguish between different possible explanations of carefully chosen phenomenal contrasts. Block (2014)'s case that the rich property of being a facial expression is presented in visual experience fits into this framework. He is rebutting the same alternative to the Rich View that Byrne focuses on: the hypothesis that the representation of thin properties is enough to explain the contrast. Block's discussion of a series of results in face-perception is designed to show that it isn't. ${ }^{22}$

The difference between Byrne's approach to the issue and mine is this. For Byrne, the only way to identify the perceptual experiences is as the conscious upshot of processes that we can identify independently of their role in producing perceptual experiences. In contrast, I think it is impossible to identify the processes that generate perceptual experiences, without taking as already understood what perceptual experiences are. We have an understanding of perceptual experiences that comes from our familiarity with them, and that understanding is robust enough to identify the experiences, but not detailed enough to settle the Rich/Thin debate. The perceptual experiences are states (or perhaps events) with the phenomenal features that typically characterize perception in the sense-modalities and combinations of them.

Carey's discussion of contact causation gives us a domain where familiarity with perceptual experience and results from experimental sciences combine to support the Rich View. Her book The Origins of Concepts (2009) synthesizes copious evidence that impressions of contact causation are insulated from many types of knowledge of what can cause what. A feather cannot launch a brick, and a shadow cannot launch or be launched by anything. But we can get impressions of launching by these things, if their

\footnotetext{
22 Another example is Di Bona (2015), who argues that being a female/male voice can be presented in auditory experience.
} 
movements meet certain parameters. Michotte (1963) argued that the parameters are purely spatio-temporal, but Carey argues that he was wrong, because representations of causation are sensitive to agential properties, such as being able to initiate movement. There's a concept of causation that's active in infancy, Carey argues, that gets applied to the outputs of modules for detecting objects. Applying the causal concept can result in purely visual representations that have all the hallmarks of perceptual experience-such as the impression of seeing a brick cause a shadow to move.

Why think that the visual experience ever represents causation, as opposed to only the spatial-temporal movement of object A and object B, when A appears to launch B? Here's an argument that moves from premises about what properties a person becomes sensitive to, to a conclusion about which properties are presented in experience: if a perceptual experience is produced by a process that is activating its sensitivity to property $\mathrm{F}$ (in this case, causation), and presenting F-ness is not precluded by the phenomenal character of the experience, then the experience presents F.

A different type of argument moves from premises about changes in a person's overall perspective, which may not consist in sensitivities to new properties, to conclusions about which properties are presented in experience. For instance, Siewert (1998) presumes that how a neighborhood looks the first time you saw it differs from how it looks once it becomes your neighborhood. Siewert's plausible-sounding phenomenological presumption doesn't establish the Rich View. But the structure of the cases he describes makes it plausible that if the phenomenal differences go with differences in which properties the experiences present, those properties are Rich. Its plausibility indirectly supports my contention about the expression of doubt. Learning that a contorted face is an expression of doubt need not always change how it looks, but it is plausible to suppose that it could.

It is sometimes said that the experiential changes in these cases are changes in attention. ${ }^{23}$ You attend to different parts of the house-façade, your neighborhood, or the contorted face. Attending to something is fundamentally a relation to it: one attends to an object, a

\footnotetext{
${ }^{23}$ See, e.g., Nanay 2011.
} 
part of an object, a spatial region, or a property $\mathrm{F}$ that something you see instantiated. The observation that attentional changes accompany the phenomenal contrast does not tell against or in favor of the Rich View. If one attends to an object, part of it, or a spatial region, the issue is which properties the experience presents them as having. If we attend to a property, then as before, the issue is whether the property is rich or thin.

Rich social properties are strong candidates for coming to be presented in experience due to acculturation. Consider the property of being a white man, which (let's suppose) you attribute to the man in the elevator. If the Thin View is right, then what's presented is instead a cluster of thin properties (or a disjunction thereof) that people acculturated to this category use. But how plausible is it that when someone's racial whiteness is perceptually salient, its salience consists entirely in the salience of thin properties? It seems more plausible that what's salient are the possibilities of action surrounding the cultural category. Whether rich social properties illustrate the Rich View or not, our understanding of both perception and culture could benefit by illuminating where they enter in the interface between the perceiver and the world. 


\section{PART 3: Byrne}

As this debate has brought out, one important disagreement between us concerns the notion of a "presented property". Siegel takes it to be explanatorily primitive, and I do not.

We will have to leave it there, but clarifications may help resolve some other issues. First, I was taking illusions to be illustrated by paradigm examples, not to be exhausted by them. If the modularity hypothesis is true, the output of the visual module marks a natural joint in the mind. Granted modularity, false output is what illusions are, and we can bring experimental work to bear on some disputed examples. Suppose an expert is fooled by a fake Royal Albert teacup, confidently pronouncing that it is genuine. Is the expert suffering from a perceptual illusion? Yes, if his visual module is delivering the misinformation that it is a Royal Albert teacup; no, if the error is located further downstream.

Second, although I have a beef with the way many philosophers talk of "perceptual experiences" (Byrne 2009), my appeal to illusions shows that I do not think that the only route to understanding is via "processes that we can identify independently of their role in producing perceptual experiences" $(\mathrm{xxx})$. Siegel and I do agree, though, that the Rich/Thin debate cannot be settled without appeal to vision science.

Third, I didn't mean to imply that the "coherence" $(\mathrm{xxx})$ of the debate turns on the truth of the modularity hypothesis, anymore than the coherence of certain questions about the tides turns on whether gravity is responsible for them. But - and I think Siegel would concede this much - the hypothesis has some significant support. And if it is true, then we may use it to argue, as I did in Part 2, that kind properties like teacuphood are not presented in experience.

A more serious bone of contention concerns that last claim. Siegel thinks that even if there is a visual module, the Rich/Thin debate does not concern its outputs. "Even if all the outputs of perceptual modules were thin, that conclusion would not entail the Thin View" (xxx). Against Siegel, suppose that the modularity hypothesis is true, and that the outputs of the visual module are thin. We can then argue for the Thin View as follows. First premise: there is no difference in how things look without a difference in the outputs 
of the visual module. Second premise: there is no difference in presented properties without a difference in how things look. Third premise: if the Rich View is true, then there can be a difference in rich presented properties with no difference in thin presented properties. By the first and second premises, any difference in presented properties will be accompanied by a difference in outputs. So, by the third premise and the supposition of thin outputs, the Rich View is false; hence the Thin View is true.

Siegel suggests at various points that the relevant category of "visual experiences" goes beyond the outputs of any visual module. That is, there can be different visual experiences, and so presumably differences in how things look, with no difference in output. Thus she will presumably resist by denying the first premise. Be that as it may, my proposal to connect the Rich/Thin debate with modularity is not idiosyncratic. According to Rips, for example, "[t]he issue of causal perception comes down to the question.... 'Do [people] have perceptual modules that respond... with an output indicating whether a causal event is taking place?"” (Rips 2011: 84; see also Scholl and Tremoulet 2000: 305-6). ${ }^{24}$

Although Siegel will be unfazed if the outputs are all thin, I will throw in the towel if some of them are rich, which brings us to the perception of causation and animacy (Scholl and Tremoulet 2000).

Let us quickly review two examples. First, Michotte's "launching effect" (mentioned by Siegel) - in effect a Siegelean phenomenal contrast. Ball B is at rest in the middle of a display; ball A enters from the left, moving towards B. When A reaches B, the latter moves off to the right. The introduction of a short delay before B moves off can make a big difference: with no delay, there seems to be exactly the thing Hume was denying, an "impression" of causation; with a delay, two events simply seem to occur successively. Second, the "wolfpack effect" (Gao et al. 2010). Here the two contrast cases involve orientated shapes and a disc, all moving randomly. If the oriented shapes points towards ("look at") the disc there is a strong impression of animacy (specifically, the orientated

\footnotetext{
${ }^{24}$ Rips also has a useful discussion of Carey's work (cited by Siegel), not examined here for reasons of space.
} 
shapes seem to be pursuing the disc). That impression is absent if the shapes are oriented orthogonally to the disc.

There is a lot to be said for the view that these effects are genuinely perceptual. For instance, Rolfs et al. (2013) found perceptual adaptation to Michottean launches, and moreover adaption specific to retinal location. However, the perceptual nature of the launching effect does not discriminate between the thin hypothesis on which the output merely concerns a complex thin relation, causation ${ }^{\mathrm{G}}$, rather than the rich relation of causation (cf. Rips 2011: 83; Hilbert and Nishimura 2015). As to what causation ${ }^{\mathrm{G}}$ is, experimental work examining the spatiotemporal cues that produce the launching effect has already gone some way to uncovering it.

Similar points go for animacy, and for Block's (2014) use of perceptual adaptation to faces ${ }^{25}$, although obviously much more discussion is needed. I do not think Block is as committal as Siegel makes him out to be (see especially 563), but in any case the thin hypothesis is particularly salient here, since 'face' has a natural thin interpretation. (Similarly for terms for facial expressions like 'happy face'.) A rich-face is something only an animal can have; in contrast, busts and some natural rock formations have thinfaces but not rich-faces. What is presented in experience, the property of being a rich-face or the "recognitionally coextensive" property of being a thin-face? The work cited by Block does not settle the issue. ${ }^{26}$

The Thin View is not irresistible, but it does have the advantage of parsimony. We already know that the visual system has a propensity for grouping stimuli into thin gestalt categories. If that propensity can account for the data, there is no need to take it to be capable of anything more.

\footnotetext{
${ }^{25}$ Fish 2013 also appeals to adaption to (inter alia) faces to argue for the Rich View; for a reply, see Briscoe 2015.

${ }^{26}$ It's also worth noting that greeble recognition, an entirely thin matter, exhibits some of the distinctive characteristics of face recognition (Gauthier and Tarr 1997).
} 


\section{References}

Anscombe, G. E. M. 1965. The intentionality of sensation: a grammatical feature. Analytical Philosophy, second series, ed. R. J. Butler. Oxford: Blackwell.

Bar, M. (ed.) 2011. Predictions in the brain: Using our past to generate a future. Oxford: Oxford University Press.

Barwise, J. 1981. Scenes and other situations. Journal of Philosophy: 369-97.

Bayne, T. 2009. Perception and the reach of phenomenal content. Philosophical Quarterly 59: 385-404.

Block, N. 2014. Seeing-as in the light of vision science. Philosophy and Phenomenological Research 89: 560-72.

Breckenridge, W. 2007. Against one reason for thinking that visual experiences have representational content. Philosophical Perspectives 21: 117-23.

Briscoe, R. 2015. Cognitive penetration and the reach of phenomenal content. The Cognitive Penetrability of Perception: New Philosophical Perspectives, ed. J. Zeimbekis and A. Raftopoulos. Oxford: Oxford University Press.

Brogaard, B. (ed.) 2014. Does Perception Have Content? Oxford: Oxford University Press.

Burge, T. 2010. Origins of Objectivity. Oxford: Oxford University Press.

Byrne, A. 2009. Experience and content. Philosophical Quarterly 59: 429-51.

Byrne, A. forthcoming. Hill on mind. Philosophical Studies.

Carey, S. 2009. The Origin of Concepts. Oxford: Oxford University Press.

Delk, J. L., and S. Fillenbaum. 1965. Differences in perceived color as a function of characteristic color. American Journal of Psychology 78: 290-3.

Di Bona, E. 2015. The thickness of auditory perception. $M S$.

Firestone, C., and B. J. Scholl. 2014. "Top-down" effects where none should be found: the El Greco fallacy in perception research. Psychological Science 25: 38-46.

$-\ldots-$. 2015. Can you experience 'top-down'effects on perception?: the case of race categories and perceived lightness. Psychonomic Bulletin \& Review 22: 694-700.

- - - forthcoming. Cognition does not affect perception: Evaluating the evidence for 'top-down' effects. Behavioral and Brain Sciences 25: 38-46.

Fish, W. 2013. High-level properties and visual experience. Philosophical Studies 162: 43-55.

Fodor, J. 1983. The Modularity of Mind. Cambridge, MA: MIT Press.

Gao, T., G. McCarthy, and B. J. Scholl. 2010. The wolfpack effect: perception of animacy iresistibly influences interactive behavior. Psychological Science 21: 1845-53.

Gauthier, I., and M. J. Tarr. 1997. Becoming a "Greeble" expert: exploring mechanisms for face recognition. Vision Research 37: 1673-82.

Greene, M. R., and A. Oliva. 2009. The briefest of glances: the time course of natural scene understanding. Psychological Science 20: 464-72.

Gross, S., T. Chaisilprungraung, E. Kaplan, J. A. Menendez, and J. Flombaum. 2014. Problems for the purported cognitive penetration of perceptual color experience and Macpherson's proposed mechanism. Baltic International Yearbook of 
Cognition, Logic and Communication Vol. 9, ed. E. Machery and J. Prinz. Manhattan, KS: New Prairie Press.

Hilbert, D. R., and S. Nishimura. 2015. Visual perception of causation. MS.

Ioannidis, J. 2005. Why most published research findings are false. PLoS Medicine 2: 0696-701.

Levin, D. T., and M. R. Banaji. 2006. Distortions in the perceived lightness of faces: the role of race categories. Journal of Experimental Psychology: General 135: 50112.

Machery, E. 2015. Cognitive penetrability: a no-progress report. The Cognitive Penetrability of Perception: New Philosophical Perspectives, ed. J. Zeimbekis and A. Raftopoulos. Oxford: Oxford University Press.

Macpherson, F. 2012. Cognitive penetration of colour experience: Rethinking the issue in light of an indirect mechanism. Philosophy and Phenomenological Research 84: 24-62.

Michotte, A. 1963. The Perception of Causality. Translated by T. R. Miles and E. Miles. New York: Basic Books.

Nanay, B. 2011. Do we see apples as edible? Pacific Philosophical Quarterly 92: 305-22.

Olkkonen, M., T. Hansen, and K. Gegenfurtner. 2012. High-level perceptual influences on color appearance. Visual Experience: Sensation, Cognition, and Constancy, ed. G. Hatfield and S. Allred. Oxford: Oxford University Press.

Olkkonen, M., T. Hansen, and K. R. Gegenfurtner. 2008. Color appearance of familiar objects: effects of object shape, texture, and illumination changes. Journal of Vision 8: 1-16.

Pendlebury, M. J. 1990. Sense experiences and their contents: A defense of the propositional account. Inquiry 33: 215-30.

Pylyshyn, Z. 1999. Is vision continuous with cognition? The case for cognitive impenetrability of visual perception. Behavioral and Brain Sciences 22: 341-65.

Rips, L. J. 2011. Causation from perception. Perspectives on Psychological Science 6: 77-97.

Rolfs, M., M. Dambacher, and P. Cavanagh. 2013. Visual adaptation of the perception of causality. Current Biology 23: 250-4.

Scholl, B. J., and P. D. Tremoulet. 2000. Perceptual causality and animacy. Trends in Cognitive Sciences 4: 299-309.

Schyns, P. G., R. L. Goldstone, and J.-P. Thibaut. 1998. The development of features in object concepts. Behavioral and Brain Sciences 21: 1-17.

Siegel, S. 2010. The Contents of Visual Experience. Oxford: Oxford University Press.

Siegel, S. 2014. Affordances and the contents of perception. Does Perception Have Content?, ed. B. Brogaard. Oxford: Oxford University Press.

Siewert, C. 1998. The Significance of Consciousness. Princeton: Princeton University Press.

Stefanucci, J. K., and M. N. Geuss. 2009. Big people, little world: the body influences size perception. Perception 38: 1782-95.

Thau, M. 2002. Consciousness and Cognition. Oxford: Oxford University Press.

Triesch, J., D. H. Ballard, M. M. Hayhoe, and B. T. Sullivan. 2003. What you see is what you need. Journal of Vision 3: 86-94. 
Witzel, C., H. Valkova, T. Hansen, and K. R. Gegenfurtner. 2011. Object knowledge modulates colour appearance. i-Perception 2: 13-49.

Zeimbekis, J. 2013. Color and cognitive penetrability. Philosophical Studies 165: 167-75.

Zeimbekis, J., and A. Raftopoulos. 2015. The Cognitive Penetrability of Perception: New Philosophical Perspectives. Oxford: Oxford University Press. 